\title{
Healthcare-associated infections in European long-term care facilities: how big is the challenge?
}

C Suetens (carl.suetens@ecdc.europa.eu)1

1. European Centre for Disease Prevention and Control, Stockholm, Sweden

Citation style for this article:

Suetens C. Healthcare-associated infections in European long-term care facilities: how big is the challenge?. Euro Surveill. 2012;17(35):pii=20259. Available online: http://www.eurosurveillance.org/ViewArticle.aspx?Articleld =20259

Europe is aging. The percentage of the population in the European Union (EU) aged 65 years and over increased from $9.6 \%$ in 1960 to $16.0 \%$ in 2010 , and is projected to increase to $29.3 \%$ (152.6 million) in $2060[1,2]$. The population aged 80 years and over is projected to increase from 16.8 million (4.1\%) in 2010 to 43.3 million (11.5\%) in 2060, almost as many as the expected percentage of children (0-14 years, $15 \%$ ) in $2060[2,3]$. At the same time, healthcare systems are striving for cost optimisation, which results, among other things, in shorter hospital stays and early discharge. These two factors combined have led to a rapid rise in the demand for nursing homes and other social and healthcare services for the elderly such as long-term care facilities (LTCFs), residential homes and home care. The Organisation for Economic Co-operation and Development (OECD) estimated that across OECD countries (these include 22 countries of the EU and European Economic Area (EEA)), about $12 \%$ of the population aged 65 years and older received some form of long-term care service in 2009 , either at home $(64.5 \%$ of the services) or in institutions (35.5\%) [3]. Based on these figures, the European Centre for Disease Prevention and Control (ECDC) estimates the number of residents in LTCFs in the EU at approximately 3.7 million in 2010, a number that will certainly increase in the coming decades.

Because of age-related dysfunctions of the immune system and physiological changes, the elderly are more sensitive to infection and therefore predisposed to the most frequent infections occurring in nursing homes: urinary tract infections, pneumonia, skin and soft tissue infections and gastro-intestinal infections, in particular those for which previous antibiotic use is a risk factor, such as Clostridium difficile infection [4]. Healthcare-associated infections in LTCFs are also associated with severe consequences including debilitation, hospital admission and sometimes death [5]. Because of the ageing population, the frequent transfer of patients from LTCFs to hospitals and back to LTCFs, the increasing prevalence of multidrug-resistant microorganisms such as meticillin-resistant Staphylococcus aureus (MRSA), extended-spectrum beta-lactamase (ESBL)-producing Enterobacteriaceae and vancomycin-resistant Enterococcus spp. (VRE), and the low availability of infection control resources in these facilities $[6,7]$, prevention and control of healthcareassociated infections in European LTCFs is becoming an increasing challenge.

The number of patients acquiring a healthcare-associated infection in acute care hospitals in the EU has previously been estimated at 4.1 million each year [6], but there is no similar estimate for LTCFS. Facing the lack of EU-wide data on healthcare-associated infections in LTCFs, ECDC provided funding for the Healthcare Associated infections in Long-Term care facilities (HALT) project from December 2008 to May 2011.

The project's aims were to support prevention of healthcare-associated-infections and antimicrobial resistance in European LTCFs and to provide a tool for the assessment of the prevalence of healthcare-associated infections, antimicrobial use as well as performance indicators for infection prevention and control practices and antimicrobial stewardship in LTCFs. A methodology for repeated point prevalence surveys tailored to the LTCF/nursing home setting was developed by HALT and implemented in a Europe-wide network of LTCFs.

The HALT project estimated that there were at least 62,000 LTCFs in the EU in 2010 , with a capacity of approximately 3.1 million beds, $58 \%$ of which were located in general nursing homes (residents needing 24 -hour medical or highly skilled nursing supervision), $32 \%$ in residential homes (residents needing 24 -hour supervision of daily activities) and $10 \%$ in mixed facilities. Even though these figures are probably an underestimate because of the difficulty to collect precise data in several countries, in particular on privately owned LTCFs, the estimated number of long-term care beds was of the same order of magnitude as the abovementioned estimate of residents in European LTCFs.

After a pilot survey in 2009 [8], a first EU-wide point prevalence survey was performed from May to September 2010, including a total of 64,007 residents surveyed in 722 LTCFs in 25 countries (Austria, Belgium, Bulgaria, Croatia, Cyprus, the Czech Republic, 
Denmark, Estonia, Finland, France, Germany, Greece, Hungary, Ireland, Italy, Lithuania, Luxembourg, Malta, The Netherlands, Poland, Portugal, Slovenia, Spain, Sweden and the United Kingdom) [9,10]. Participating LTCFs were nursing homes (75\%), mixed facilities (15\%) and residential homes ( $7 \%)$.

Signs and symptoms of an infection were reported for $2,495(4.0 \%)$ of the 61,932 eligible residents, but following the application of the case definitions to the collected signs and symptoms, these were only confirmed as a healthcare-associated infections in 1488 (2.4\%) residents. The most frequently reported types of healthcare-associated infection were respiratory tract infections (33.6\%), urinary tract infections (22.3\%), skin and soft tissue infections (21.4\%), conjunctivitis ( $8 \%$ ) and gastro-intestinal infections (4.6\%). Among the eligible residents, $4.3 \%$ received at least one antimicrobial agent. The five most prescribed antimicrobials were amoxicillin-clavulanic acid (12.7\%), nitrofurantoin (10.4\%), trimethoprim (9.9\%), amoxicillin (7.3\%) and ciprofloxacin $(6.9 \%)$. Almost half $(48.9 \%)$ of all antimicrobial agents in participating LTCFs were prescribed for a urinary tract indication. Uroprophylaxis represented $27.7 \%$ of all prescribed antimicrobial agents in participating LTCFs.

Based on the results of this point prevalence survey, and assuming an occupancy rate of $95 \%$ [11], the number of LTCF residents with signs and symptoms of an infection on any given day in the EU is estimated at 117,800 or 140,600 , depending on the denominator used. With an average duration of an infection episode of 10 days, the total number of infections in LTCFs in EU/EEA countries could be estimated at 4.3 million each year based on signs and symptoms, of which 2.6 million would be confirmed as healthcare-associated infections according to the case definition. Using a different method based on an average annual incidence rate of 4.4 (range: 2.2-6.0) healthcare-associated infections per 1,000 resident-days from recent studies in developed countries [12-16], the number of infections in LTCFs could be estimated at 4.7 million each year, similar to the above-mentioned prevalence-based estimate. Because residents stay in LTCFs for long periods of time, from two to 60 months on average according to the country [11], and may have more than one infection per year, the number of individual residents acquiring these infections is likely to be substantially lower.

This week's and last week's issue of Eurosurveillance report on two point prevalence surveys performed using the HALT methodology, in Frankfurt am Main [17] and in the Netherlands [18]. While the latter survey was part of the European HALT survey (May to September 2010), the former was performed independently and during a different time period (January to March 2010). Both surveys reported a relatively low prevalence of healthcare-associated infections $(4.3 \%$ and $2.8 \%$, respectively). The possible reasons for the large differences compared with the results of previously published surveys are discussed by the authors, as well as some of the methodological issues which are currently addressed in the follow-up European project funded by ECDC (HALT-2), including case definitions of healthcare-associated infections in LTCFs. This improved European surveillance methodology will be implemented in 2013 in a second survey of healthcare-associated infections and antimicrobial use in European LTCFs [8], as a next step of ECDC's efforts to support EU Member States in assessing the effect of implemented prevention and control measures and to raise the awareness about infection control and antimicrobial stewardship in European LTCFs.

Acknowledgments

The HALT project (ECDC Grant/2008/04) was awarded to a consortium lead by the Université Claude Bernard Lyon (J. Fabry) in collaboration with the Belgian Scientific Institute of Public Health (B. Jans, K. Latour), the Agenzia Sanitaria e Sociale Regionale Bologna (ML. Moro) and the Health Protection Agency London (B. Cookson). 


\section{References}

1. Eurostat. Population projection scenario 2010 (EUROPOP2010). Luxembourg: European Commission. [Accessed 29/08/2012]. Available from: http://epp.eurostat.ec.europa.eu/statistics_ explained/index.php/Population_projections

2. Directorate-General for Economic and Financial Affairs. The 2012 Ageing Report: Underlying Assumptions and Projection Methodologies. Brussels: European Commission; 2011. ISBN 978-92-79-19298-2. doi: 10.2765/15373. Available from: http:// europa.eu/epc/pdf/2012_ageing_report_en.pdf

3. Organisation for Economic Co-operation and Development (OECD), Health at a Glance 2011: OECD Indicators. Paris: OECD; 23 Nov 2011. ISBN : 9789264126107 (HTML); 9789264111530 (print). DOI : 10.1787/health_glance-2011-en. Available from: http://dx.doi.org/10.1787/health_glance-2011-en

4. Gavazzi G, Krause KH. Ageing and infection. Lancet Infect Dis. 2002;2(11):659-66.

5. Koch AM, Eriksen HM, Elstrøm P, Aavitsland P, Harthug S. Severe consequences of healthcare-associated infections among residents of nursing homes: a cohort study. J Hosp Infect. 2009;71(3):269-74.

6. European Centre for Disease Prevention and Control (ECDC). Annual epidemiological report on communicable diseases in Europe 2008. Chapter 2. Healthcare-associated infections. Stockholm: ECDC; 2008. Available from: http://ecdc. europa.eu/en/publications/publications/0812_sur_annual_ epidemiological_report_2008.pdf

7. van Buul LW, van der Steen JT, Veenhuizen RB, Achterberg WP, Schellevis FG, Essink RT, et al. Antibiotic use and resistance in long term care facilities. J Am Med Dir Assoc. 2012;13(6):568. e1-568.e13.

8. Latour K, Jans B, Moro ML, Fitzpatrick F, Ricchizzi E, Dillane T, et al. Healthcare-associated infections and antimicrobial use in European long-term care facilities (HALT-2), 22nd European Congress of Clinical Microbiology and Infectious Diseases (ECCMID); London, United Kingdom; 31 March-3 April 2012. Available from: http://halt.wiv-isp.be/report/Posters/Forms/ Alltems.aspx

9. Latour K, Jans B, the HALT management team. Healthcare associated infections in long-term care facilities. Results of the pilot point prevalence survey. Brussels: The Scientific Institute of Public Health (WIV-ISP), November 2009. Deposit number D/2011/2505/8; IPH/Epi-report number: 2011-006. Available from: http://halt.wiv-isp.be/report/Reports/HALT-1/HALT\%20 Report\%20Pilot\%20Survey\%20Nov\%202009.pdf

10. Moro ML, Jans B, Latour K, Ricchizzi E, Cookson B, MacKenzie $\mathrm{D}$, et al. Healthcare associated infections (HAI) in long-term care facilities in Europe. BMC Proceedings 2011;5(Suppl 6): P157.

11. Broex E, Jans B, Latour K, Goossens H, ESAC Management Team. European Surveillance of Antimicrobial Consumption (ESAC): Results from the national survey of characteristics of nursing homes. Brussels: The Scientific Institute of Public Health (WIV-ISP); October 2010. ISBN: 9789057283017. Available from: http://www.nsih.be/download/nursing_homes/ ESAC NATSURV NH.pdf

12. Eriksen HM, Koch AM, Elstrøm P, Nilsen RM, Harthug S, Aavitsland $\mathrm{P}$. Healthcare-associated infection among residents of long-term care facilities: a cohort and nested case-control study. J Hosp Infect. 2007;65(4):334-40.

13. Heudorf U, Schulte D. Surveillance nosokomialer Infektionen in einem Altenpflegeheim Inzidenz und Risikofaktoren. [Surveillance of nosocomial infections in a long-term care facility. Incidence and risk factors]. Bundesgesundheitsblatt Gesundheitsforschung Gesundheitsschutz. 2009;52(7):732-43. German.

14. Engelhart ST, Hanses-Derendorf L, Exner M, Kramer $\mathrm{MH}$. Prospective surveillance for healthcare-associated infections in German nursing home residents. J Hosp Infect. 2005;60(1):46-50.

15. Smith M, Bull AL, Richards M, Woodburn P, Bennett NJ. Infection rates in residential aged care facilities, Grampians region, Victoria, Australia. Healthcare Infection. 2011;16(3):116-20.

16. Lim CJ, Mclellan SC, Cheng AC, Culton JM, Parikh SN, Peleg AY, et al. Surveillance of infection burden in residential aged care facilities. Med J Aust. 2012;196(5):327-31.

17. Heudorf U, Boehlcke K, Schade M. Healthcare-associated infections in long-term care facilities (HALT) in Frankfurt am Main, Germany, January to March 2011. Euro Surveill. 2012;17(35): pii=20256. Available online: http://www. eurosurveillance.org/ViewArticle.aspx?Articleld $=20256$

18. Eilers R, Veldman-Ariesen MJ, Haenen A, van Benthem BH. Prevalence and determinants associated with healthcareassociated infections in long-term care facilities (HALT) in the Netherlands, May to June 2010. Euro Surveill. 2012;17(34): pii=20252. Available from: http://www. eurosurveillance.org/ViewArticle.aspx?Articleld =20252 